\title{
Determining the relationship between ethical environment climate and tending to desertion in the small and medium industries
}

\author{
Seyed Bayazid Hosseini ${ }^{1 *}$, Mostafa Baghbanian ${ }^{2}$ and Reza Shafaie ${ }^{3}$ \\ ${ }^{1}$ Master of Business Administration student at Azad University, Sanandaj,Iran; gelavan.paychoon@gmail.com \\ ${ }^{2}$ Faculty Member of Islamic Azad University, Sanandaj Iran; baghbanyan@yahoo.com \\ ${ }^{3}$ Assistant professor and faculty member of the University of Kurdistan, Sanandaj Iran; shafeai@yahoo.com
}

\section{Article history:}

Received date: 22 May 2020

Review date: 18 June 2020

Accepted date:25 July 2020

\section{Keywords:}

ethics, organizational climate, ethical

climate, tending to desertion.

\begin{abstract}
This study aims to survey the relationship between ethical environment and tending to be desertion in the small and medium industries of the Sanandaj city (Chemical industry cluster). For this purpose, all the employees of these companies were examined in terms of population and 310 of them were chosen according to Morgan Table. The research method id descriptive and correlational. This study is practical in terms of purpose and survey in terms of method of data collection. Accordingly, Babinet.al standard inventory to assess ethical climate and Dickonik and Stillwell'sinventory were used to assess tending to desertion. The reliability of the questionnairewas calculated in terms of Cronbach's alpha for the variables listed as 0.885 and 0.893, respectively. For inventory's validity, content validity and with the opinions of advisors and some professors were confirmed.The final results of the study in SPSS software showed a significant inverse relationship between ethical climate and a desire to desertion in the company under investigation..
\end{abstract}

Please cite this article as Hosseini SB., Baghbanian M., Shafaie R. 2020. Determining the relationship between ethical environment climate and tending to desertion in the small and medium industries. ALKHAS; The Journal of Environment, Agriculture and Biological Sciences, 2(3), $13-18$

\section{Introduction}

One major concern for managers in recent years was increasing the intentional exit of human resources and tending for staff turnover.Failure to maintain proper management staff as the most important institutional investors, in addition to imposing direct and indirect costs, it causes the transfer of functions and ultimately the loss of competitive advantage to competitors [1]. With increasing competition and the development of human resource development, organizations are trying to keep their talented employees and empower them so that they can exhibit high performance; but organizations often fear that it will lose its human resources and will damage, because by losing valuable forcesin each organization, it will suffer the loss of skills and experience that has been achieved over the years of efforts [2].However, an important factor in the development of internal communication and conditions of employment is ethical climate that has a significant effect on organizational productivity [3].Organizations consider moral issues, because people expect them to show high levels of ethical standards [4].Employees who perceived their organizations ethically find it suitable for their understanding and may affect their satisfaction [5].Several studies confirmed the impact of moral values and ethical climate of organization on

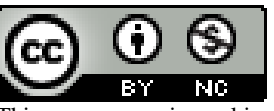


organizational commitment[6], role conflict [7], job satisfaction and turnover [8] that makes the importance of this study twofold.

\section{Research Theoretical Foundations}

\section{2-1. Ethical climate}

Ethical climate is part of the general atmosphere of the organization. According to Victor and Cullen (1988) [9], ethical climate in the organization refers shared perceptions of morally correct behavior and that how the ethical issue should be managed. Also Victor Vokalen presented a framework for measuring staffs' perceptions of ethical direction by combining theoretical structures of cognitive development, moral theory and analysis sites. Ethical climate is a framework for creation and strengthening of acceptable norms, values and beliefs that may be related thisinstitutional view of "how things should be done" [3].Researchers in the past ten years have studied the ethical work climate through its impact on the ethical behavior of employees. These studies have examined how the ethical work climate affect behaviors and staff's occupational attitudesso that in this study, the effects of ethical work climate on the variables such as job satisfaction and organizational commitment, job stress and intention of jobmovements have been discovered [10].Ethical climate of the organization refers common and widespread decision of people in the organization in dealing with ethical issues and feedback they receive. In fact, it can be said that the different dimensions of moral spacemay provide different signs for members of a working group that what is acceptable behavior and what is unacceptable behavior [11].

\section{2-2. Tending to desertion}

Today organizations have strong competition with each other to attract workers with knowledge and expertise [12].Traditional organizations are designed to meet the needs of individuals in the first three levels of Maslow's hierarchy pyramid and current organizations do not supply great situations to maintain loyalty and staffs' commitment. The need to preserve efficient human forces requires organizations to implement higher levels of human needs, i.e. self-esteem, respect [13].To avoid employee turnover as a strategic goal [14], there are factors other than material things [15]. As recruiting talented and experienced force is very difficult, it is important to maintain forces.Because maintaining these forces eliminates additional costsrelated to recruit new forces and also prevent desertion and their absorption by competitors and the loss of valuable organizational knowledge (ibid). Increasing employee turnover will make organization relations with customers and suppliers makes difficult [16].Scientific findings show that staff desertion results fromconscious and deliberate intention of employees for job turnover [17]. Organizations need powerful tactics to keep employees who minimize intentional desertion. It is important to review intention for desertion, for determining whether an employee is reluctant to leave state can enable organizations to take measures to protect workers [18].

\section{Review of Literature}

In a study in 2013 by Khowang and Tainentitled factors influencing job satisfaction and employee turnover through banks in the city of Ho Chi Minh, they concluded that management support and providing good working environment and teamwork makes the employees' job satisfaction and their loyalty [19].Elsie and Alpkan did a research in 2009 to study the impact of ethical climate on job satisfaction among 62 Telecom Companies in Turkey;their findings showed that the self-interest aspect of ethical climate has a negative effect on job satisfaction [3].Caboli and Sanei in 2014did a research as the factors affecting the leave or continue employees in Semnan Province Court and concluded thatorganizational commitment, job satisfaction, organizational justice, perceived organizational support and psychological contract have a significant negative impact on employee turnover [20].

\section{Research Conceptual Model}




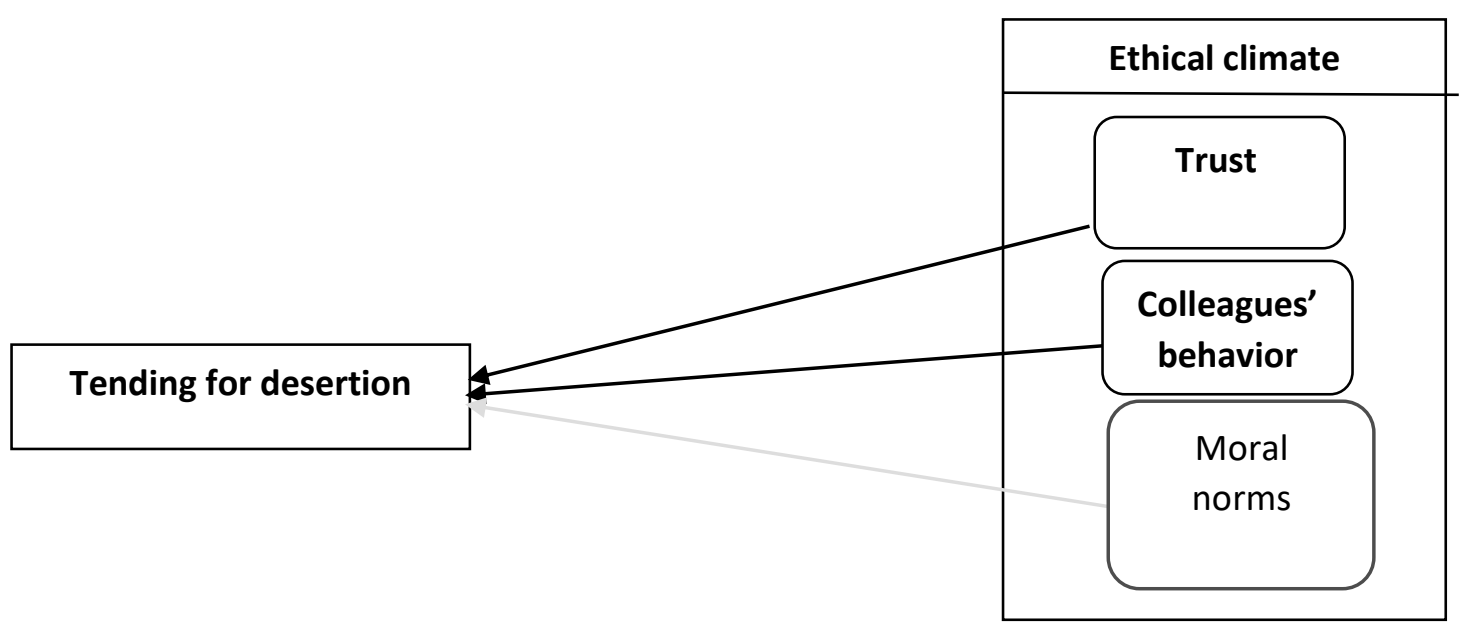

Source: ethical climate of Babin te.al (2000) [21] and tending to desertion by Dickonic and Stilwell (2004) [22]

\section{Research Hypotheses}

5-1. the main hypothesis of this study

There is a significant relationship between ethical climate and employee turnover intentions.

5-2. Research secondary hypotheses

1. There is a significant relationship between trust and willingness to desertionof staff.

2. There is a significant relationship between colleagues' behavior and intention to staffs' desertion.

3. There is a significant relationship between moral norms and intention to staffs' desertion.

\section{Research method}

This study is practical in terms of objective and descriptive in terms of data collection method. Also, correlation method was used in describing the relationship between the two variables. The study population consisted of all the employees of small and medium industries in the city of Sanandaj (chemical industry clusters) that their number is equal to 1570 people. The number of total samples using Morgan Table is 310 people. To assess ethical climate, Babin et.al standard inventory (2000) [21] and Deconinck\& Stilwell's standard inventory was used to assess intention for desertion which 11 of which are based on the Likert scale. Cronbach's alpha was used to determine the reliability of the questionnaire that its value for all ethical climate variables and intention for desertion equals 0.885 and 0.893 . To test the validity, according to their standard methods, content validity method was used and its content validity was confirmed by a number of experts in the field. SPSS software was used to analyze information gathered.

\section{Analysis of data}

\section{7-1. Inferential statistics}

In inferential statistics section, parametric tests were used according to Kolmogorov-Smirnov test (K-S) and proving normality of data distribution. To survey the main hypothesis and auxiliary hypotheses of the Pearson, correlation coefficient was used.

\subsection{Research hypotheses}

7.2.1. Reviewing main hypothesis of the research:

$\mathrm{H}_{0}: \rho=0$ 
There is no significant relationship between ethical climate and a desire to leave.

$\rho \neq 0 \mathrm{H}_{1}$ :

There is a significant relationship between ethical climate and desire to leave

Table 1: Results of Pearson correlation between ethical climate and tend to desertion

\begin{tabular}{|c|l|c|}
\hline \multirow{2}{*}{$\begin{array}{c}\text { Ethical } \\
\text { climate }\end{array}$} & $\begin{array}{l}\text { Pearson } \\
\text { Correlation }\end{array}$ & -0.664 \\
\cline { 2 - 3 } & Sig & 0.000 \\
\cline { 2 - 3 } & \multicolumn{2}{|c|}{$\mathrm{N}$} \\
\hline
\end{tabular}

Source: Research data

According to Table 1, as the level of significance is less than 0.05 , it is concluded that the H_0 hypothesis is not confirmed and $\mathrm{H} \_1$ hypothesis indicating the relationship between ethical climate and turnover intentions is confirmed.So there is aninverse and significant relationship between ethical climate and a desire to leave at $95 \%$ the service and its correlation coefficient equal to -0.664 .

\subsubsection{Surveying secondary research hypotheses:}

The results of the sub-hypotheses are given in Table 2 below which shows that the correlation coefficient for the relationship between ethical climateincludes trust, behavior with colleagues and ethical norms and willingness to desertionare $0.648,0.712$ and 0.519 , respectively and its significant number of error value is 0.05 . Therefore, research secondary hypotheses are confirmed.

\section{Results and Discussion}

The main hypothesis of the study, based on the correlation coefficient is - 0.664 is accepted and confirmed with confidence (95\%).In line with the results of the study hypothesis, Khvang and Tyne (2013) [19], Elsie and Alpkan (2009) [3] and Akpara and Vine (2008) [4] have achieved similar results in their research results.According to the first hypothesis, the correlation coefficient (0.648) is accepted and was approved with confidence (95\%). Second sib-hypothesis given the correlation coefficients 0.712 with confidence $95 \%$ was confirmed. The third sub-hypothesis given the correlation coefficient 0.519 is accepted and confirmed with confidence $95 \%$.

\section{Conclusion and suggestions}

It is suggested that corporate executives and decision makers highlight and the Code of Ethics in the organization space and its emphasis andpromotionamong the staff to increase adherence to a moral code by its employees. The companies were only required to work with brokers and agents who followed the company's ethical standards and have knowledge and professionalism to provide correct guidance to customers. They must also be constantly monitored and fraud and unethical behavior will not be tolerated them in any way. Therefore, the selection and screening of brokers should also include theirfinancial and moralrecords. With the participation of workers and the freedom to do things and create an atmosphere of collaborative decision-making and strict observance of rules and efforts to achieve the specified goals of the company, managers create the ethical climate in the company.It is suggested that managers provide a basic level of organizational communication in a desirable amountto share experiences and new ideas their employees tend to be between the partners in the company.Executives and corporate decision makers do encourage teamwork among employees and reduce their individual work to increase understanding between employees. 
Table2. Pearson correlation test between the dimensions of ethical climate and the desire to leave

\begin{tabular}{|c|c|c|}
\hline & Tendi & \\
\hline \multirow[t]{2}{*}{ Trust } & $\begin{array}{c}\text { Pearson correlation } \\
\text { coefficient }\end{array}$ & 0.648 \\
\hline & Sig & 0.000 \\
\hline \multirow{2}{*}{ Colleague's behavior } & $\begin{array}{c}\text { Pearson correlation } \\
\text { coefficient }\end{array}$ & 0.712 \\
\hline & Sig & 0.000 \\
\hline \multirow{2}{*}{ Ethical norms } & $\begin{array}{c}\text { Pearson correlation } \\
\text { coefficient }\end{array}$ & 0.519 \\
\hline & Sig & 0.000 \\
\hline
\end{tabular}

\section{References:}

[1].Clebbeek, A. C., \&Bax, E. H. (2004). Is high employee real harmful? An empirical test using compact records. Academy Journal of Management, 47, 277-286.

[2].Hom P.W, Griffeth, R.W. (1990). Structural equations modeling test of a turnover theory: crosssectional and longitudinal analyses. J ApplPsychol; V :T० - 7 (June).

[3].Elci, M. and Alpkan, L. (2009). The impact of perceived organizational ethical climate on work satisfaction. Journal of Business Ethics. 84: 297-311.

[4].Okpara, O., Wynn, J. (2008). The impact Ethical climate on job satisfaction, and commitment in Nigeria. Journal of Management Development. 9. 54-63.

[5].Koh, H. C. \& Boo, E. H. (2001). The link between organizational ethical and job satisfaction; Journal of Business Ethics.29, 309-324.

[6].Mulki JP, JF, Locander, WB. (2006). Effects of ethical climate and supervisory trust on salesperson's job attitudes and intentions to quit. J Pers Sell Sales Manage 2006; 26:119-32.

[7]. Jaramillo, F., Mulki, J., Soloman, p. (2006). The role of ethical on salesperson role stress, gob attitudes, turnover intenion, and job performance, The Journal of Personal Selling Management. 26(3).44-62

[8].Deconinck, James B. (2011), “ The influence of ethical climate on marketing employees job attitudes and behavior ", Journal of Business Research, No.63, PP:384-391

[9]. Victor, B. Cullen, B. (1988). A theory and measure of ethical climate in organizations. Administrative Science Quarterly. 33, 101-125.

[10]. Parker PP, Baltes BB, Young SA, Huff JW, Altmann RA, Lacost HA,(2003), Relationships between psychological climate perceptionsand work outcomes: a meta-analytic review. J Organ Behav:389-416. 
[11]. Cullen, J., B., B.Victor\&C.Stephens (1989). " An ethical weather report: Assessing the organizations ethical climate", Organizational Dynamics, No, 18, PP:50-63.

[12]. Martin, Graeme. Phillip Beaumont. Rosalind doig, Judy Pate. (2005). A New Performance Discourse for HR? European Management Journal, Vol. 23, No. 1, p. 76-88.

[13]. Senge, Peter (2005), five commands to create a learning organization, translated by Hafiz Kamal Hedayat, published by Industrial Management Institute, Tehran.

[14]. Saadat, Esfandyar. (1986), human resource management, SAMT publication, $1^{\text {st }}$ edition, Tehran.

[15]. Zeeman, Sergio (2006), advertising as we knowreached the end, translated byManizheh Sheikh Javadi, Tehran: Siteh Publication.

[16]. Miller, John Moore, David (2006), trade namesbusiness, translated by AtiehBathaie, Rasa Publications.

[17].Tett, R.P \& Meyer, J.P. (1993). " Job satisfaction ,organizational commitment, turnover intention, and turnover: Path analyses based on meta-analytic findings". Personnel Psychology, 46, 259-293.

[18].Handlon, R.S. (2009). The departure of the insurance agent: The impact organizational commitment, organizational justic, and job satisfaction have on intent to leave in the insurance industry, August.

[19].Khuong, M, N. and Tien, B, D. (2013). Factors influencing employee loyalty directly and indirectly through job satisfaction - A study of banking sector in Ho Chi Minh City, International Journal of Current Research AndAcacemic Review, Volume 1 Number 4, pp. 81-95.

[20]. Caboli, Maliha and Sanei, Mehdi. (2014), the factors affecting the desertion or continuingof judiciary staffs' services at Semnan Province, the Master's thesis, Islamic Azad University, Shahrood Branch, Department of Human Sciences.

[21].Babin, BJ, Boles JS, Robin D.P. (2000). Representing the perceivedethical work climate among marketing employees. J Acad MarkSci; 28(3):345-58

[22].Deconinck, J, Stilwell, D. (2004). Incorporating organizational justice, role states, pay satisfaction and supervisor satisfaction in a model of turnover intentions. J Bus Res 2004; 57:225-31. 